\title{
Parotid Gland Warthin Tumor
}

National Cancer Institute

\section{Source}

National Cancer Institute. Parotid Gland Warthin Tumor. NCI Thesaurus. Code C66865.

An adenoma that arises from the parotid gland. It is characterized by an oncocytic, often papillary, epithelial component, dense lymphoid stroma, and cystic spaces. A strong association with smoking has been reported. It typically presents as a painless swelling in the lower portion of the parotid gland. 